\title{
ABS Dynamic Simulation Test Stand using Lab View
}

\author{
Patil Rohini B. \\ M. Tech. (Electronics) \\ Department of Technology, Shivaji University \\ Kolhapur, Maharashtra, India
}

\author{
Bombale Uttam L., PhD \\ Associate Professor, M. Tech. \\ Department Of Technology, Shivaji University \\ Kolhapur, Maharashtra, India
}

\begin{abstract}
Anti-lock braking system (ABS) is an automobile safety system for vehicles which will allow controlling wheels of vehicle and providing safety contact on road surface according to driver braking input, avoiding uncontrolled skidding and also preventing the wheels from locking up. The main task of ABS is to press and release the brakes almost 15 times a second, so process of stopping the vehicle in a shorter time and distance. The ABS controller basically prevents the braking wheel from skidding on the road surface. Because of all these features, ABS has greatly improved the performance of automobile security. Currently the test stand is used to take measurements and analysis of ABS. The ABS system performs two main functions, automatic measurement and testing of high quality ABS. In this paper, the test stand can create a virtual environment so that various testing conditions can be applied for ABS system. The test stand can record all the parameters and compare with stored values, and simultaneously apply for Lab View software. This Software is used to calculate varies parameters of the test stand and also generate graph which shows running status test stand.
\end{abstract}

\section{Keywords}

ABS Test stand, Data acquisition, Virtual instrument.

\section{INTRODUCTION}

Modern motor vehicle drive systems are characterized by a multitude of complex control and regulating systems optimally adapting the drive characteristics to the respective driving condition. In the vehicles more and more control unit area active and supervise innumerable functions. Known systems are electronic devices for regulating the brake system to obtain increased safety. One of the latest improvements is an ANTILOCK BRAKE SYSTEM, which as the name suggests, prevents a vehicle's brakes from locking up and skidding during hard stops on wet or icy roads.

The ABS controller basically prevents the braking wheel from skidding on the road surface. This is based on the knowledge that a skidding or spinning wheel has less traction and side stability than a rolling wheel (Demel and Hemming, 1989). Under ideal road conditions it usually takes a few seconds to brake a car to stop, but less than one second to lock-up a wheel.

The electronic control unit (ECU) is programmed to decelerate each wheel near its peak slip condition without locking the wheel. By pulsating the brake pressure, up to 15 times per second, the controller admits the wheel to alternate between free rolling and braking during the pulse cycle. This controlled pulsing thereby preserves the ability to steer the vehicle in the desired direction while braking in a slippery road.

The existing information about the availability and reliability of these systems is insufficient. Furthermore, it is not defined, how these systems can be effectively checked on their correct function. At present, the efficiency of these systems is only tested after the production of the car and no further tests or periodic checking occurs. It is unknown, whether these selfcheck are sufficient to cover most of the failures which appear in the system, or if additional efficiency tests are necessary.

To check and calibrate these systems in the vehicles omeoptimized measurements and diagnostic devices are required. ABS performance directly affects the vehicle driving safety; smooth ABS performance test also has become the inevitable trend of the automobile industry development. The main objective of the system is to test ABS instead of real vehicle. There are three purposes to design the ABS dynamic simulation test stand:

- Under different circumstances the ABS should work good

- Maximum friction factor should be consider during testing

- To minimize the cost and test cycle

Conventional power test benches and/or conventional brake test benches are inadequate for developing and testing complex drive systems like ABS because of their testing conditions. The traditional test stand has two common Testing conditions:

- Test for the real vehicle

- The friction coefficient between road and tire is difficult to change.

However, the test stand described in this paper has improvements on these two points. To test the performance of ABS, we have created a virtual environment by using ABS dynamic simulation test stand to imprecise the external condition. Instead of testing actual vehicle, it only test the ABS mechanism

\section{LITERATURE REVIEW}

In this paper [1], in the process of ABS design, development and validation, traditional test methods like road test did poor in cost, cycle and flexibility, and it is difficult to test the control effect in various conditions. Sosome manufacturers use the test stand instead of road test to do itIn paper [2], the functional behavior of older ABS systems is examined with a four wheel ABS Test Bench from TUEV Rheinland. The vehicles for the tests are acquired during the periodical inspection tests at the TUEV Kraftfahrt testing facilities.

In [3], a method for building a HIL of simulation a hydraulic Antilock Braking System (ABS) based on MATLAB/Simulink is presented in this paper. This paper [4] describes the preliminary research and implementation of an experimental test bench set up for an electric vehicle antilock braking system (ABS)/traction control system (TCS) representing the dry, wet and icy road surfaces. A fuzzy logic based controller to control the wheel slip for electric vehicle antilock braking system is presented. 
The activity has then been focused on the development of a three-dimensional model of the dynamics of a railway vehicle for more complex applications in [5]. In [6], the first paper established the mathematical model of motor drive current based on instantaneous rotational speed and other measurable parameters, and then proposed a control model by completely using the electric inertia simulation equivalent moment of inertia, furthermore carried on the appraisal.This paper [7], introduces the concept of automotive electronic control technology, modern automotive electronic control system applications and the development of feelings of automotive electronic control technology. In paper [8], Measurement and examination of DC motor are important issue for ensuring quality of portable washing machine. Automatic measuring and examining can save much time and improve identification accuracy. It is very helpful for keeping high quality of products. In this paper, an automatic measurement and examination platform based on powerful LabView is designed and implemented. LabView is easy for monitoring and data acquisition. Motor parameters are recorded and analyzed simultaneously by applying LabView. Automatic measurement and examination of DC motor with high performance is developed in this paper.

In the [9] paper, it is introduced that the design of a power quality monitoring system based on LabView for factory power quality, with LabView as development platform, composed by some functional modules such as data acquisition, data processing, data storage, and data report. This paper [10] provides details about the integration of the electrical/electronic component and the control system. A bench-top air-to-water heat pump was designed, developed, and constructed. This experimental apparatus is currently being used to demonstrate to undergraduate students some thermodynamics and heat transfer concepts and principles. A PC-based control system which consists of LabView and data acquisition (DAQ) unit is employed to monitor and control this experimental laboratory apparatus.

\section{HARDWARE}

The schematic diagram of test stand shows the main components given in Fig. 1. It consists of Lab view driver, feedback control circuit, ADC and DAC interfaces, RS 232 interface, dual power supply also some peripheral equipment load cell, load cell interface, speed measurement circuit, electromotor and wheel.

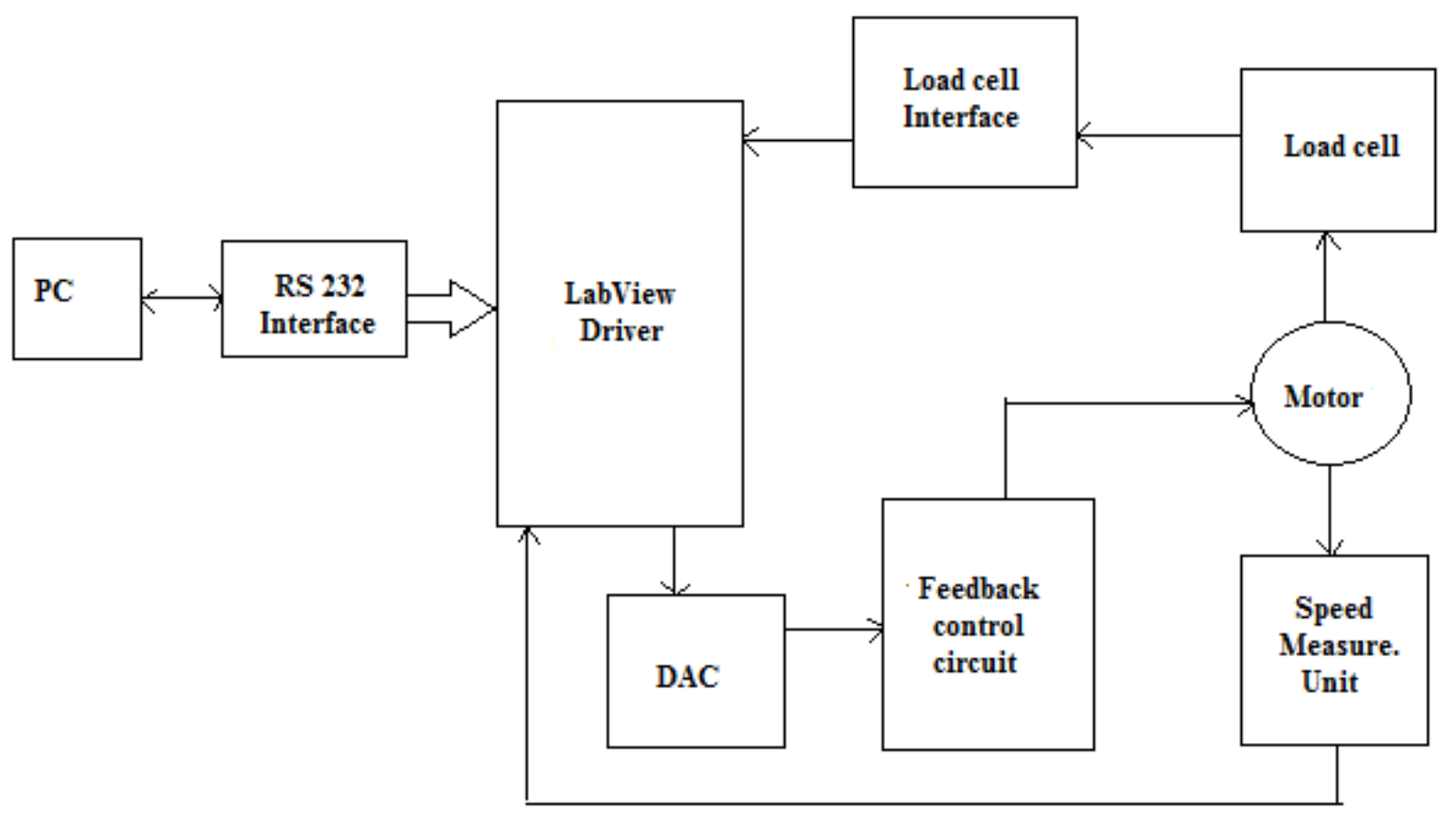

Fig 1: Block diagram of the test stand

\section{DATA ACQUISITION AND PROCESSING}

The main function of ABS is to compare signals which are transmitted by wheel speed sensors and then calculate difference between them. The test stand can create virtual environment to test performance of ABS.

Simple wheel is used so as to analyze the single round; it is driven by the electro-motor. The load cell will measure the torque on the shafts while braking. Speed of the wheel is measured with help of flywheel by using integrated LED/phototransistor module interfaced with LabView driver.
Then these two signals are transmitted to the data acquisition unit simultaneously. The torque is always proportionate to the exciting current. The torque generated between the motor driving shaft and the wheel shaft can be controlled by changing the exciting current. In order to control the exciting current of the motor, the control signal is also transmitted from virtual instruments to data acquisition hardware. The hardware contains not only acquisition unit but control unit.

To communicate between PC and real time data acquisition hardware which is used to monitor system for technological process, the communication module can be realized as application through which we are interconnecting data control 
with virtual instruments. The used sensors convert electric and non-electric analogical process data into electrical signals. These electrical signals must be converted from time continuous variation into a digital representation under binary form for process the data on PC. By processing data through PC using virtual instrumentation software provides two advantages, first is to establish a connection with process through universal serial bus and second is to release the communication with monitoring and data acquisition unit.

\section{SOFTWARE}

\subsection{Lab VIEW}

LabView $^{\mathrm{TM}}$ is centerpiece of graphical interface that is a software package which provides graphics-based programming language designed specifically for the creation of virtual instruments (VI) for both data acquisition and analysis with the tools you need to create and deploy measurement and control system. Automatic measurement and examination platform based on powerful software Lab VIEW is designed and implemented. Parameters of the test stand are recorded and analyzed simultaneously by applying LabView.

The block schematic of the software developed using LabView, When the port number is provided, the execution enters the while loop. All the structures come inside the while loop with each of them having separate execution for true and false conditions. Some of the structures are interlinked according to the logic of execution. The output from each structure is manipulated using decimal to number converter. These manipulated values visualized in the display panel.

Fig. 2 shows the display panel consisting of a Com port, speed, torque, break pressure, speed torque graph. First the display panel is turned on and the port number is selected. Now the wheel is start moving. Speed of wheel is display on panel also on speed graph. When we apply force on brake pedal that particular break pressure and torque is display on panel.Fig.3 show first graph of instantaneous speed and torque with respect to time, and fig. 4 is of second graph shows speed with respect to time on display panel.

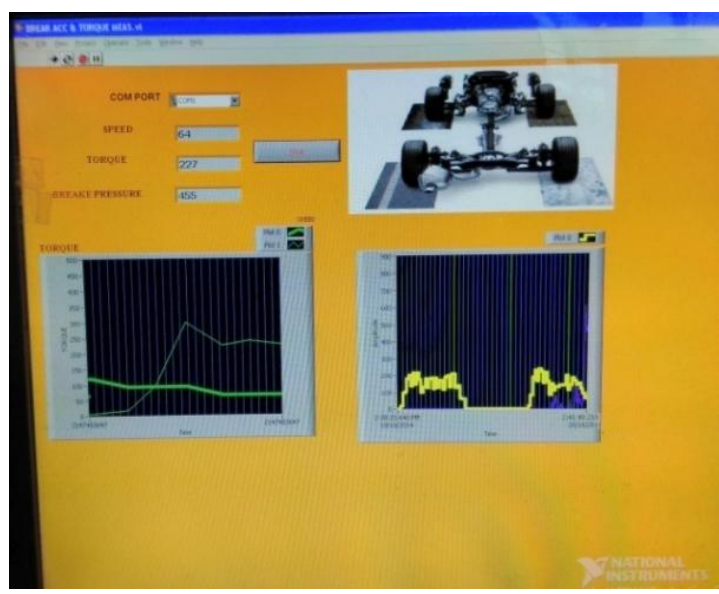

Fig 2: Display panel

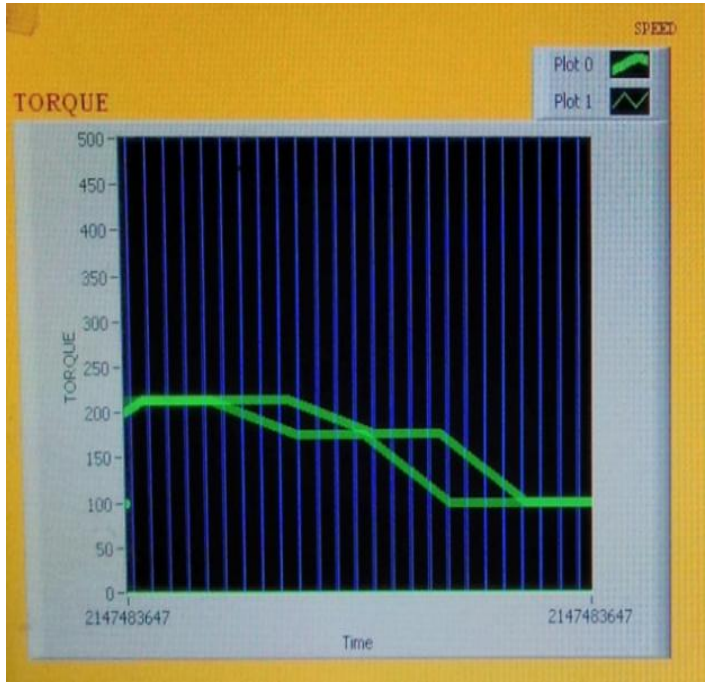

Fig 3: Graph of Torque and Speed

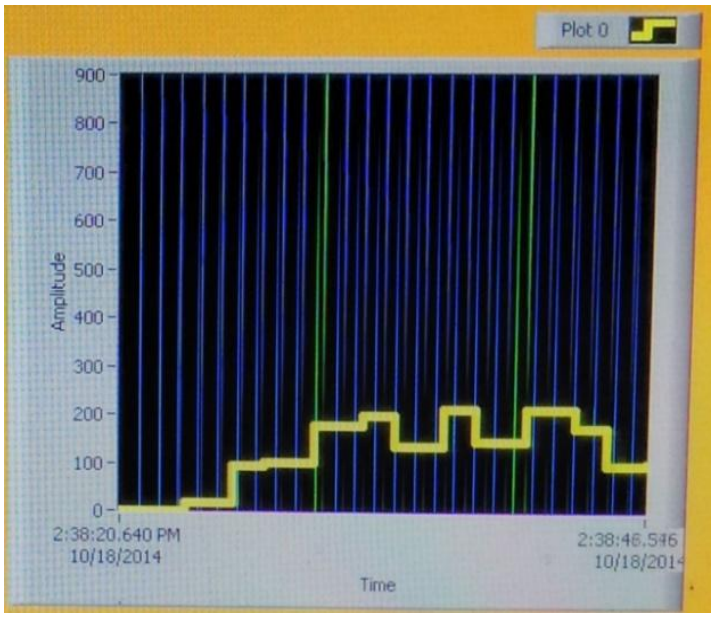

Fig 4: Graph of Speed

In future LabView can be programmed to graphically analyze, acquire data, control and monitor the ABS performance test. The instantaneous speed can be visualized using the analog speedometer and the speed graph. If the speed is exceeded, proper indication will be provided in the display panel. Also more sensors may be integrated and the communication can be made wireless.

\section{CONCLUSION}

The real time simulator for data acquisition and analysis of ABS tester using LabView was designed. The use of LabView helped to reduce many devices and it served as a useful display panel. The results of the test carried out with this method have shown that the data acquisition system has a substantially good performance. The test stand can make ABS work effectively. It can replace the road test of the real vehicle, reduce the test cost and shorten test cycle significantly. In future, more sensors may be integrated and the communication can be made wireless.

\section{ACKNOWLEDGMENTS}

This work was carried out in Shivaji University, Kolhapur. The Instrumentation laboratories and software laboratory were used for testing of various stages of this design work. 


\section{REFERENCES}

[1] "Data Acquisition System Based on LabVIEW for ABS Dynamic Simulation Test Stand", IEEE Engineering Research Center of Automotive Electronics, vol. 1, pp. 292-295, 2010

[2] Thomas Frese, Dr. GerdHeuser, "Testing of existing AntiLock Braking systems (ABS)",TÜV Kraftfahrt GmbH Institute of Traffic Safety, vol. 216, pp. 95-105, 2002.

[3] J. Li, F. Yu and J. Zhang, "The rapid development of a vehicle electronic control system and itsapplication to an antilock braking system based on hardware-in-theloopsimulation," J. A. Engineering, vol. 216, pp. 95-105, 2002.

[4] P. Khatun, C. M. Bingham, N. Schofield, and P. H. Mellor, "An experimental laboratory bench Setup to study electric vehicle antilock braking/traction systems and their control,"IEEE Vehicular Technology Conference, Birmingham, Alabama.

[5] E. Meli, M. Malvezzi, S. Papini, L. Pugi, M. Rinchi and A. Rindi, "A railway vehicleultibodymodel for real-time applications," Vehicle System Dynamic, vol. 46, pp. 1083-1105, 2008

[6] H. Von, "Brake testing machine with moment-of-inertia simulation,"Elektro-Anzeiger, vol. 34, pp. 49-53, 1981.

[7] X. D. Wang, Electronic Controlled Device of Automobile and Application. Beijing: China Machine Press, 2007.

[8] C. L. Cheng, J. C. Yeh, S. C. Chern and Y. H. Lan, "Automatic Testing System Based on LabVIEW for DC Motor of Portable Washing Machine," IEEE Industrial Electronics and Applications Conference, pp. 489-493, 2008.

[9] Q. Tang, Z. S. Teng, S. Y. Guo and Y. N.Wang, "Design of Power Quality Monitoring System Based on LabVIEW," 2009 International Conference on Measuring Technology and Mechatronics Automation, vol. 1, pp. 292-295, 2009.

[10] H. I. Abu-Mulaweh and D.W. Mueller, "The use of LabView and data acquisition unitto monitor and control a bench-top air-to-water heat pump," Computer Applications in Engineering Educationvol. 16, pp. 83-91, 2008. 2218 